УДК 54.05

\title{
СИНТЕЗ И ИЗУЧЕНИЕ МЕДЬСОДЕРЖАЩИХ ПОЛИМЕРОВ НА ОСНОВЕ СУЛЬФАТОВ АРАБИНОГАЛАКТАНА
}

\author{
() Б.Н. Кузнецов ${ }^{1,2 *}$, Н.Ю. Васильева ${ }^{1,2}$, А.В. Левданский ${ }^{1}$ Н.Г. Максимов ${ }^{1}$, А.С. Казаченко ${ }^{1}$, \\ Г.П. Скворцова ${ }^{1}$, L. Djakovitch L. ${ }^{3}$, C. Pinel ${ }^{3}$ \\ ${ }^{1}$ Институт химии и химической технологии СО РАН, ФИЦ КНЦ СО РАН, \\ Академгородок, 50-24, Красноярск, 660036 (Россия), e-mail: inm@icct.ru \\ ${ }^{2}$ Сибирский федеральный университет, пр. Свободный, 79, Красноярск, \\ 660041 (Россия) \\ ${ }^{3}$ IRCEL YON, 2 avenue Albert Einstein,F-69626 Villeurbanne Cedex, Lyon (France)
}

Впервые методом ионного обмена осуществлен синтез водорастворимых медьсодержащих сульфатов арабиногалактана. Изучены их состав и строение методами элементного и химического анализа, рентгеноспектрального микроанализа, атомно-силовой микроскопии (AСM), инфракрасной спектроскопии (ИКС), электронного парамагнитного резонанса (ЭПР).

По данным метода АСМ поверхность пленок медьсодержащего полимера не имеет посторонних включений и состоит из однородных кристаллитов, имеющих сферическую и слегка вытянутую форму и поперечные размеры порядка 100 нм. Состав медьсодержащих полимеров был изучен с использованием химического метода и рентгеноспектрального микроанализа. Отсутствие азота в полученном полимере свидетельствует о полном замещении катионов аммония в аммонийной соли сульфата АГ на катионы меди. ИК-спектр медьсодержащего сульфата АГ подобен спектру натриевой соли сульфатированного арабиногалактана.

В спектре ЭПР медьсодержащего сульфата АГ наблюдается суперпозиция двух сигналов. Один из них принадлежит изолированным ионам $\mathrm{Cu}^{2+}$, другой - обменносвязанным ионам $\mathrm{Cu}^{2+}$ в солеподобных соединениях. Интегральная интенсивность сигналов изолированных ионов $\mathrm{Cu} 2+$ (анизотропный сигнал) и обменносвязанных ионов (изотропный сигнал) зависит от содержания меди в полимере.

Водорастворимые медьсодержащие полимеры сульфатов АГ имеют перспективы использования в медицине.

Ключевые слова: сульфатированный арабиногалактан, ионный обмен, медьсодержащие полимеры, изолированные и обменносвязанные ионы $\mathrm{Cu}^{2+}$.

Работа выполнена при финансовой поддержке РФФИ и Правительства Красноярского края в рамках научного проекта № 16-43-242083. В работе использованы приборы Красноярского регионального ичентра коллективного пользования СО РАН.

Кузнецов Борис Николаевич - заведующий лабораторией доктор химических наук, профессор, Институт химии и химической технологии СО РАН, заведующий кафедрой, Сибирский федеральный университет, тел.: (391) 249-48-94, e-mail: bnk@icct.ru Васильева Наталья Юрьевна - старший научный сотрудник, кандидат химических наук, доцент, тел.: (391) 205-19-42, e-mail: vasilyeva.nata@mail.ru Левданский Александр Владимирович - научный сотрудник, кандидат химических наук, тел.: (391) 205-19-42, e-mail: alexsander.1@mail.ru Максимов Николай Геннадьевич - ведущий научный сотрудник, кандидат химических наук, тел.: (391) 205-19-42, e-mail: inm@icct.ru

Продолжение на с. 50

\section{Введение}

При создании новых лекарственных веществ широко используют полисахариды растительного происхождения [1]. Наиболее распространенные полисахариды, применяемые для фиксации лекарственных веществ, - это декстран, целлюлоза, крахмал, карбоксиметилцеллюлоза. В последнее время возрастает интерес к использованию для этих целей арабиногалактана (АГ), выделяемого из древесины лиственницы, который является водорастворимым и обладает сравнительно невысокой молекулярной массой [2].

\footnotetext{
* Автор, с которым следует вести переписку.
} 
В литературе описаны методы синтеза водорастворимых нанокомпозитов арабиногалактана с биогенными металлами: с железом, медью, кобальтом, никелем, цинком, платиной и серебром [2-4]. Для получения биологически активных металлсодержащих полимеров перспективно применение сульфатированного арабиногалактана (САГ), который способен взаимодействовать с катионами различных металлов $[5,6]$.

Цель данной работы - разработка простого способа синтеза водорастворимых медьсодержащих полимеров сульфатированного арабиногалактана (Си-САГ), основанного на ионном обмене, и изучение их строения методами ИК- и ЭПР-спектроскопии.

\section{Экспериментальная часть}

В качестве исходного сырья использовали арабиногалактан древесины лиственницы сибирской (Larix sibirica Ledeb.) производства ООО «Химия древесины» (Иркутск, Россия) под наименованием препарата «ФиброларС».

Получение сульфатов АГ осуществляли по методике [5] сульфатированием АГ сульфаминовой кислотой в диоксане с последующим выделением САГ в виде аммониевой соли (содержание серы 10,0-12,0\% вес.). Натриевую соль САГ получали из его аммониевой соли. Для этого к водному раствору аммониевой соли САГ добавляли небольшое количество $10 \% \mathrm{NaOH}$, смесь нагревали на кипящей водяной бане, пока не улетучится весь аммиак. Эту операцию повторяли несколько раз до полного удаления аммиака. Полноту удаления аммиака проверяли при помощи фильтровальной бумаги, смоченной раствором $\mathrm{Hg}_{2}\left(\mathrm{NO}_{3}\right)_{2}$. После замещения $\mathrm{NH}_{4}{ }^{+}$на $\mathrm{Na}^{+}$полученный водный раствор натриевой соли САГ упаривали до небольшого объема в вакууме водоструйного объема и выделяли, как описано для исходной аммониевой соли.

Получение медьсодержащих полимеров сульфатированного арабиногалактана (Cu-CAГ). $\mathrm{Cu}-\mathrm{CA \Gamma}$ получали из его аммониевой соли методом ионного обмена с использованием ионообменной смолы КУ-2-8 в $\mathrm{Cu}^{+}$-форме по стандартной методике [7]. Предварительно ионообменную смолу КУ-2-8, вырабатываемую в промышленности в $\mathrm{Na}^{+}-$-орме, переводили в $\mathrm{Cu}^{2+}$-форму. Для этого через слой ионообменной смолы КУ$2-8$ в $\mathrm{Na}^{+}$-форме, помещенной в виде гомогенной смеси с дистиллированной водой в вертикальную стеклянную колонку диаметром 20-25 мм, длиной 300-350 мм, снабженную внизу краном, пропускали водный раствор сульфата меди (II). Затем через слой подготовленного катионита пропускали раствор 2,0-2,5 г очищенной путем диализа аммониевой соли САГ в 25 мл дистиллированной воды. После прохождения через колонку 25 мл раствора соли САГ смолу в колонке промывали дистиллированной водой (3 раза по 25 мл). Собирали промывные жидкости и упаривали раствор на ротационном испарителе до 10-15 мл при температуре перегонки не более $50{ }^{\circ} \mathrm{C}$. Из полученного в результате отгонки остатка выделяли Сu-САГ путем высаживания в 100 мл этанола. Образовавшийся осадок - Cu-САГ отфильтровывали, промывали на фильтре 15-25 этанола, высушивали под вакуумом. Сu-САГ хранили для дальнейшего использования в вакуум-эксикаторе при температуре $<5^{\circ} \mathrm{C}$.

Образцы медьсодержащих сульфатированных производных арабиногалактана с различным содержанием меди $-2,8 ; 6,1 ; 7,2$ и 9,4\% (масс.) получали из аммониевой соли САГ методом ионного обмена в статическом режиме при различном соотношении содержания обменных ионов $\mathrm{Cu}^{2+}$ в катионите к содержанию групп $-\mathrm{OSO}_{3}{ }^{-}$в $\mathrm{CAГ}$. Для этой цели 1 г аммонийной соли САГ, соответствующий 0,3 мг-экв групп $-\mathrm{OSO}_{3}^{-}$, растворяли в 5 мл дистиллированной воды, добавляли катионит КУ-2-8 в $\mathrm{Cu}^{2+}$-форме в количествах, соответствующих 0,$5 ; 1,0 ; 2,0$ и 4,0 мг-экв обменных ионов $\mathrm{Cu}^{2+}$. Образовавшиеся смеси раствора аммонийной соли САГ и катионита перемешивали в течение 30 мин., затем катионит отфильтровывали. Медьсодержащие образцы САГ с указанным выше содержанием меди получали путем испарения воды из соответствующего раствора на гладкой поверхности.

ИК-спектры АГ и продуктов его сульфатирования сняты с использованием ИК-Фурье спектрометра

Казаченко Александр Сергеевич - младший научный сотрудник, тел.: (391) 205-19-42, e-mail:malenkii-krolik@mail.ru

Сквориова Галина Павловна - научный сотрудник, тел.: (391) 205-19-42, e-mail: galina.skv@bk.ru Djakovitch Laurent - Directeur de Recherches, e-mail: laurent.djakovitch@ircelyon.univ-lyon1.fr Pinel Catherine - Directrice, e-mail: catherine.pinel@ircelyon.univ-lyon1.fr
Tensor-27 (Bruker, Германия) в области длин волн 400-4000 $\mathrm{cm}^{-1}$. Обработка спектральной информации проведена по программе OPUS (версия 5.0). Твердые образцы для анализа готовили в виде таблеток в матрице $\mathrm{KBr}$ (2 мг образца / 1000 мг $\mathrm{KBr}$ ). Спектры ЭПР регистрировали на приборе ЭПР Фурье-спектрометр «BRUKER ELEXSYS 
E580» в режиме CW при комнатной температуре. Мощность СВЧ - 0,2 мВт, величина модуляции - 1 Гс (Gs). Моделирование спектров проводили с помощью программ X Sophe, взаимное вычитание спектров проводили с помощью встроенных программ. Исследования строения металлоцентров в фазе сульфатированного полисахарида проводили согласно методикам [8, 9].

Содержание серы в сульфатированных производных арабиногалактана определяли по модифицированной методике [10] сжиганием в токе кислорода с последующим поглощением продуктов сжигания пероксидом водорода и титрованием щелочью в присутствии индикатора метилового красного. Содержание азота осуществляли на элементном анализаторе Flash EA-1112 (Thermo Quest Italia). Определение ионов меди (II) в медьсодержащем производном сульфатированного арабиногалактана проводили методом комплексонометрического титрования ЭДТА с индикатором мурексид [11]. Для сравнения содержание серы, азота и меди также определяли на приборе ТM-1000 Hitachi (Япония) с рентгеноспектральным анализатором Swift ED-TM EDX.

\section{Результаты и обсуждение}

Для получения Сu-САГ методом ионного обмена был использован катионит КУ-2-8 в $\mathrm{Cu}^{2+}$-форме.

Ионному обмену подвергали аммонийную соль сульфатированного АГ:

$$
\mathrm{A} \Gamma-\mathrm{OSO}_{3} \mathrm{NH}_{4}+\mathrm{RSO}_{3}(\mathrm{Cu} / 2) \rightarrow \mathrm{A} \Gamma-\mathrm{OSO}_{3}(\mathrm{Cu} / 2)+\mathrm{RSO}_{3} \mathrm{NH}_{4},
$$

где $\mathrm{RSO}_{3}$ - катионит КУ-2-8.

Ионный обмен проводили в динамическом режиме, при соотношении содержания обменных ионов в КУ-2-8 к содержанию групп $\mathrm{NH}_{4}^{+}$, равном 60-70 : 1 (мг/экв : мг/экв).

Состав Сu-САГ с высоким содержанием меди был определен с использованием химического метода и рентгеноспектрального микроанализа (табл. 1). Отсутствие азота в полученном продукте свидетельствует о полном замещении катионов аммония на катионы меди. Содержания серы и меди в полученном образце, определенные различными методами, совпадают (табл. 1).

Медьсодержащие полимеры сульфатированного арабиногалактана - водорастворимые аморфные порошки серо-зеленого цвета. При испарении воды из их водных растворов на полиэтиленовой подложке они выделяются в виде прозрачных пленок зеленого цвета.

По данным атомно-силовой микроскопии инородные включения на поверхности пленки отсутствуют (рис. 1), что указывает на высокую чистоту полученного полимера.

Как видно из рисунка 1, поверхность медьсодержащего сульфата арабиногалактана состоит из однородных кристаллитов, имеющих сферическую или слегка вытянутую форму и поперечные размеры порядка 100 нм.

ИК-спектр Cu-САГ подобен спектру натриевой соли сульфатированного арабиногалактана, но существенно отличается от спектра его аммониевой соли сульфатированного арабиногалактана (рис. 2).

В ИК-спектре аммониевой соли имеется интенсивная полоса поглощения при $1450 \mathrm{~cm}^{-1}$, соответствующая колебаниям N-H связей катиона аммония. Полосы поглощения в области 3434-2925 см-1, соответствующие валентным колебаниям О-Н и С-Н связей, уширяются за счет наложения полос поглощения валентных колебаний N-H связей в катионе аммония.

В отличие от ИК-спектра аммониевой и натриевой солей в ИК-спектре (Cu-CAГ) происходит увеличение интенсивности полосы поглощения в области $1644 \mathrm{~cm}^{-1}$, характерное для деформационных колебаний $\delta(\mathrm{H}-\mathrm{O}-\mathrm{H})$, скорее всего связанное с большей степенью гидратированности этого производного сульфатированного арабиногалактана, что определяется способностью ионов меди (II) образовывать аквакомплексы. Наблюдается также уширение и расщепление полосы поглощения сульфатной группы в области 1200-1264 см ${ }^{-1}$, соответствующей валентным колебаниям vas $(\mathrm{O}=\mathrm{S}=\mathrm{O})$, возможно, это связано с различным характером взаимодействия между центральным ионом металла с сульфатными группами, находящимися в различных положениях макромолекулы.

Образцы Сu-САГ с различным содержанием меди были изучены методом ЭПР. Обнаружено, что характеристики ЭПР спектров различаются для образцов с низким (2,8\% масс.) и высоким $(9,4 \%$ масс.) содержанием меди (рис. 3). 
Таблица 1. Результаты исследования состава Сu-САГ

\begin{tabular}{c|c|c}
\hline \multirow{2}{*}{ Элемент } & \multicolumn{2}{|c}{ Содержание, \% (масс.) } \\
\cline { 2 - 3 } & Метод определения \\
\cline { 2 - 3 } & химический & РСМА \\
\hline $\mathrm{Cu}$ & 9,0 & 9,4 \\
$\mathrm{~S}$ & 8,9 & обнаружено \\
$\mathrm{N}$ & не обнаружено & . \\
\hline
\end{tabular}
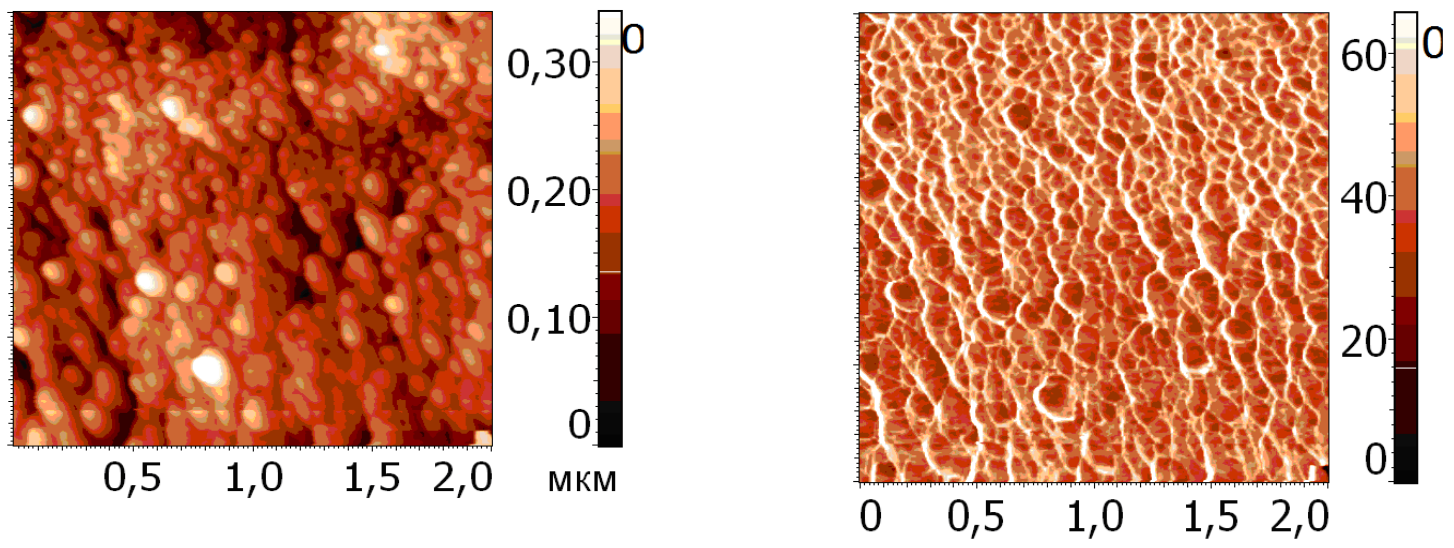

Рис. 1. Типичные АСM (полуконтактная мода) изображения рельефа (слева) и фазового контраста (справа) пленки медьсодержащего сульфата арабиногалактана

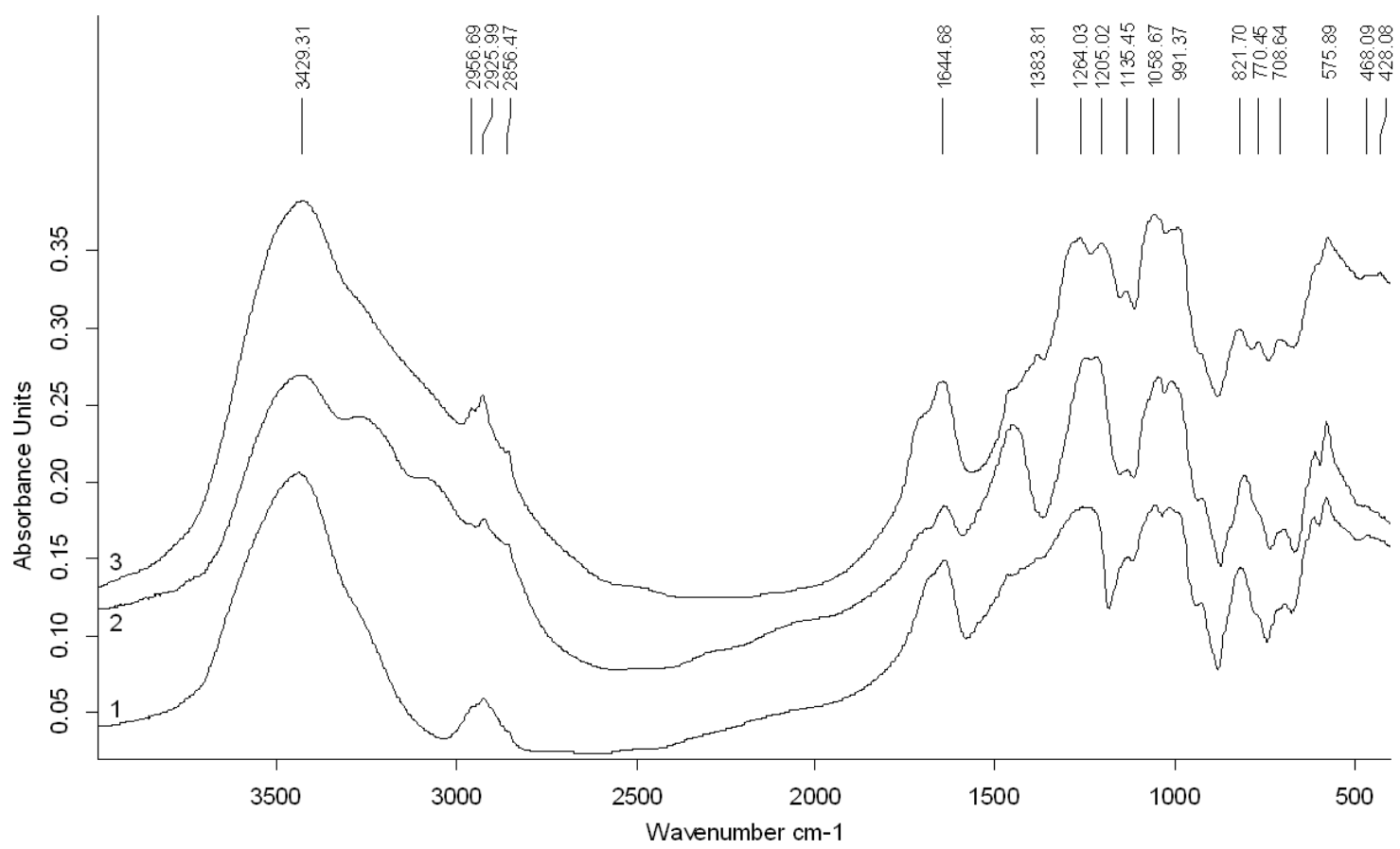

Рис. 2. ИК-спектры: натриевой (1), аммониевой (2) солей и медьсодержащего полимера сульфатированного арабиногалактана (3)

В спектре ЭПР медьсодержащего производного САГ наблюдается суперпозиция двух сигналов, которые можно найти путем взаимного вычитания [8]. Один из них характерен для изолированных ионов $\mathrm{Cu}^{2+}$, в котором наблюдается сверхтонкая структура, разрешенная в параллельной ориентации (A $\left.\| 128 \cdot 10^{-4} \mathrm{~cm}^{-1}\right)$. В области, перпендикулярной ориентации, сверхтонкая структура не разрешена ввиду малых значений констант сверхтонкой структуры, однако возможно определить ее значение $(g \perp 2,086)$ методом компьютерного моделирования сигнала ЭПР. Подобные значения параметра ЭПР $\left(A \perp 15 \mathrm{~cm}^{-1}, \mathrm{~g} \| 2,408\right)$ характерны для ионов $\mathrm{Cu}^{2+}$, находящихся в координации слегка вытянутого кислородного октаэдра $[8,9]$ (искаже- 
ния связаны с наличием эффекта Яна-Тейлера). Близкие аналогичные параметры имеют ионы $\mathrm{Cu}^{2+}$ в тутоновых солях либо в октаэдре в различных оксидах (MgO) [8], комплексах $\mathrm{Cu}^{2+}$ с пектином [12] и в ионообменной целлюлозе [13]. Следует отметить, что параметры спектров $\mathrm{Cu}^{2+}$ определяются расщеплением $\mathrm{d}$-уровней, величиной расщепления и степенью делокализации электронов. Значения параметров спектра ЭПР изолированных ионов меди в Сu-САГ соответствуют значению расщепления d-орбитали в октаэдрическом поле из анионов кислорода для $\mathrm{Cu}^{2+}$.

В ЭПР спектре $\mathrm{Cu}-\mathrm{CAГ}$ также наблюдается линия, близкая к симметричной, которая может быть обусловлена наличием магнитных взаимодействий между катионами $\mathrm{Cu}^{2+}$. Эти взаимодействия появляются при расстоянии между ионами меди меньше 8-10 А.. Диполь-дипольные взаимодействия приводят к уширению линий, не меняя в целом параметров спин-гамильтониана. Обменные взаимодействия между одинаково ориентированными катионами относительно внешнего магнитного поля приводят к смазыванию сверхтонкой структуры, однако значения g-фактора остаются неизменными. Если отсутствует порядок во взаимной ориентации взаимодействующих ионов меди, то происходит усреднение значений g-факторов, что приводит к появлению общего перехода и соответственно появлению симметричного сигнала в спектрах ЭПР (g $\left.\mathrm{g}_{\text {ср. }}=2,17\right)$.

В таблице 2 приведены данные об изменении интегральной интенсивности сигналов изолированных ионов $\mathrm{Cu}^{2+}$ (анизотропный сигнал) и обменносвязанных ионов $\mathrm{Cu}^{2+}$ (изотропный сигнал) в зависимости от содержания меди в образце.

Отсюда следует, что интегральная интенсивность изолированных ионов спадает с ростом содержания меди в образце, в то время как интенсивность от обменносвязанных ионов возрастает. Образование локальных областей с высокой концентрацией обменносвязанных ионов в структуре образца $\mathrm{Cu}-\mathrm{CAГ}$, вероятно, связано с наличием в полисахариде участков с повышенной локальной концентрацией сульфатных групп. Обменносвязанным ионам $\mathrm{Cu}^{2+}$ соответствует симметричный сигнал в ЭПР спектре (рис. 3б). Анализ формы линии этого сигнала показал, что низкопольная часть сигнала ЭПР аппроксимируется Лоренцовой формой, а высокопольная - больше соответствует Гауссовой форме. Это указывает на частичное упорядочивание взаимной ориентации. Анализ ЭПР спектров образцов САГ с низким содержанием меди свидетельствует в пользу того, что изолированные ионы $\mathrm{Cu}^{2+}$ находятся в координации искаженного кислородного октаэдра с различными лигандами ( $\mathrm{R}-\mathrm{OH}, \mathrm{R}-\mathrm{OSO}_{3}$ и $\left.\mathrm{H}_{2} \mathrm{O}\right)$.

$a$

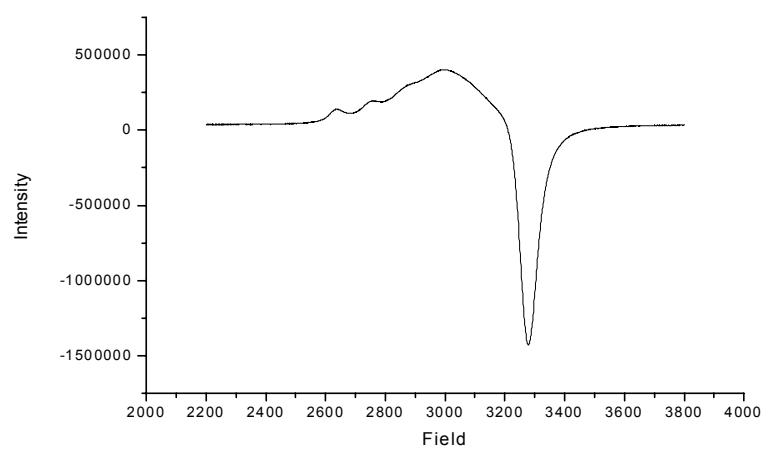

$\sigma$

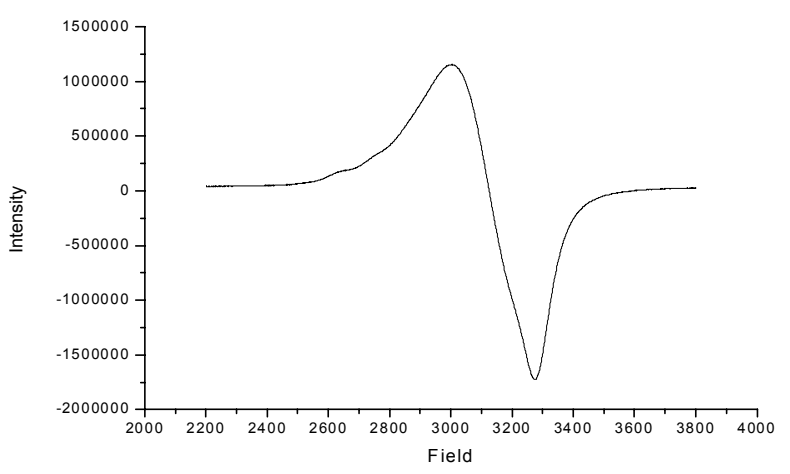

Рис. 3. ЭПР-спектры образцов медьсодержащих полимеров сульфатированного арабиногалактана, содержащих $2,8 \%$ вес. (a) и 9,4\% вес. (б) меди

Таблица 2. Изменение относительного количества изолированных и обменносвязанных ионов ионов $\mathrm{Cu}^{2+}$ в зависимости от содержания меди в Сu-САГ

\begin{tabular}{c|c|c}
\hline \multirow{2}{*}{$\begin{array}{c}\text { Содержание меди в Сu-САГ, \% } \\
\text { (масс.) }\end{array}$} & \multicolumn{2}{|c}{ Относительное количество ионов $\mathrm{Cu}^{2+}, \%^{*}$} \\
\cline { 2 - 3 } & изолированные ионы & обменносвязанные ионы \\
\hline 2,8 & 73 & 40 \\
6,2 & 64 & 61 \\
7,1 & 40 & 92
\end{tabular}

* Вычислено из интегральных интенсивностей соответствующих сигналов в спектре ЭПР. 


\section{Заключение}

В результате проведенного исследования установлена возможность использования метода ионного обмена для получения водорастворимых медьсодержащих полимеров на основе аммонийных солей сульфатов арабиногалактана. Катионы $\mathrm{Cu}^{2+}$ в медьсодержащих полимерах САГ находятся в виде октаэдрических комплексов изолированных ионов на участках с малой локальной концентрацией сульфатных групп и в виде частично упорядоченных солеподобных соединений на участках с высоким локальным содержанием сульфатных групп. Соотношение изолированных и обменносвязанных ионов $\mathrm{Cu}^{2+}$ можно регулировать путем вариации содержания меди в сульфате арабиногалактана. Поверхность пленок медьсодержащего полимера не имеет посторонних включений и состоит из однородных кристаллитов сферической и слегка вытянутой формы с поперечным размером около 100 нм.

Водорастворимые медьсодержащие полимеры сульфатов арабиногалактана могут найти применение при создании новых лекарственных средств.

\section{Сиисок литература}

1. Reis R.L., Neves N.M., Mano J.F., Gomes M.E., Marques A.P., Azevedo H.S. Natural-based polymers for biomedical applications. Cambridge: Woodhead Publishing Limited, 2008. 832 p.

2. Медведева Е.Н., Бабкин В.А. Остроухова Л.А. Арабиногалактан лиственницы - свойства и перспективы использования (обзор) // Химия растительного сырья. 2003. №1. С. 27-37.

3. Бабкин В.А, Остроухов Л.А, Иванова С.З., Иванова Н.В., Медведева Е.Н., Малков Ю.А., Трофимова Н.Н., Федоров Т.Е. Продукты глубокой химической переработки биомассы лиственницы. Технология получения и перспективы использования // Журнал Российского химического общества им. Д.И. Менделеева. 2004. Т. 48, №3. С. 62-69.

4. Сухов Б.Г., Александрова Г.П., Грищснко Л.А., Феоктистова Л.П., Сапожников А.Н., Пройдакова О.А., Тьков А.В., Медведева С.А., Трофимов Б.А. Нанобиокомпозиты благородных металлов на основе арабиногалактана: получение и строение // Журнал структурной химии. 2007. Т. 48, №5. С. 979-984.

5. Vasil'eva N.Yu., Levdansky A.V., Kuznetsov B.N., Skvortsova G.P., Kazachenko A.S., Djakovitch L., Pinel C. Sulfation of arabinogalactan by sulfamic acid in dioxane // Russ. J. Bioorganic Chem. 2015. Vol. 41, N7. P. 725-731.

6. Васильева Н.Ю., Левданский А.В., Карачаров А.А. Мазурова Е.В., Бондаренко Г.Н., Левданский В.А., Казаченко А.С., Кузнецов Б.Н. Изучение строения продуктов сульфатирования арабиногалактана из древесины лиственницы хлорсульфоновой кислотой в пиридине // Журнал Сибирского федерального университета. Химия. 2014. Т. 7, N4. C. 547-555.

7. Zagorodni A.A. Ion Exchange Materials: Properties and Applications. Amsterdam: Elsevier, 2006. 456 p.

8. Abragam A., Bleaney B. Electron Paramagnetic Resonance of Transition Ions. Oxford: Clarendon Press, 1970. 700 p.

9. Альтшулер С.А., Козырев Б.М. Электронный парамагнитный резонанс соединений элементов промежуточных групп. М., 1972. 670 c.

10. Черонис Н.Д., Ма Т.С. Микро- и полумикрометоды органического функционального анализа. М., 1973. 576 с.

11. Подчайнова В.Н., Симонова Л.Н. Аналитическая химия элементов. Медь. М., 1990. 279 с.

12. Карасева А.Н., Миронов В.Ф., Цепаева О.В., Выштакалюк А.Б., Минзанова С.Т., Карлин В.В., Миндубаев А.З. Полиметаллокомплексы пектиновых полисахаридов и их биологическая активность // Химия и компьютерное моделирование. Бутлеровские сообщения. 2004. Т. 5, №1. С. 33-35.

13. Красильникова С.В., Грунин Ю.Б., Смирнова Л.Г. Вишневская Г.П., Хонг Я.Ш., Ли Ч.Х., Волков В.И. Особенности взаимодействия ионов $\mathrm{Cu}^{2+}$ и $\mathrm{Mn}^{2+}$ с ионообменной целлюлозой по данным электронного парамагнитного резонанса // Структура и динамика молекулярных систем. 2007. Т. 1. С. 454-457.

Поступило в редакиию 18 ноября 2016 г.

После переработки 21 ноября 2016 г. 
Kuznetsov B.N..$^{1,2^{*}}$, Vasilyeva N.Yu. ${ }^{1,2}$, Levdansky A.V. ${ }^{l}$, Maximov N.G. ${ }^{l}$, Kazachenko A.S. ${ }^{l}$, Skvortsova G.P. ${ }^{l}$, Djakovitch L. ${ }^{3}$, Pinel $C^{3}{ }^{3}$ SYNTHESIS AND STUDY OF COPPER-CONTAINING POLYMERS OF SULFATED ARABINOGALACTAN

${ }^{I}$ Institute of Chemistry and Chemical Technology SB RAS, FRC KSC SB RAS, Akademgorodok, 50-24, Krasnoyarsk 660036 (Russia), e-mail: inm@icct.ru

${ }^{2}$ Siberian Federal University, pr. Svobodny, 79, Krasnoyarsk, 660041 (Russia)

${ }^{3}$ IRCELYON, 2 avenue Albert Einstein F-69626 Villeurbanne Cedex, Lyon, France

For the first time, the synthesis of water-soluble copper-containing sulfates of arabinogalactan was accomplished by ion exchange method. Their composition and structure were studied by elemental and chemical analysis, AFS, FTIR, ESR methods. According to AFM data the surface of films of copper-containing polymer has no impurities and consists from homogeneous crystallites of spherical and slightly elongates shape with the transversal sizes near $100 \mathrm{~nm}$. The composition of copper-containing polymers was studied by chemical method and by spectral microanalysis. The absence of nitrogen in the obtained polymers points on the complete substitution of ammonium cations in the ammonium salt of AG sulfate on the cations of copper.

FTIR spectrum of copper-containing sulfate of AG is similar to spectrum of sodium salt of AG sulfate. The superposition of the two signals was observed in ESR spectrum of $\mathrm{Cu}$-containing AG sulfate. One of them belongs to isolated $\mathrm{Cu}^{2+}$ ions, the other - to accociated ions $\mathrm{Cu}^{2+}$ in the salt-like compounds. The integral intensity of isolated $\mathrm{Cu}^{2+}$ (anisotropic signal) and associated $\mathrm{Cu}^{2+}$ (isotropic signal) depends on the content of copper in the polymer. Water soluble copper-containing polymers of AG sulfates have prospects for the use in medicine.

Keyword: arabinogalactan sulfates, ion exchange, water-soluble copper polymers, composition, structure.

\section{References}

1. Reis R.L., Neves N.M., Mano J.F., Gomes M.E., Marques A.P., Azevedo H.S. Natural-based polymers for biomedical applications. Cambridge: Woodhead Publishing Limited, 2008. 832 p.

2. Medvedeva E.N., Babkin V.A. Ostroukhova L.A. Khimiia rastitel'nogo syr'ia, 2003, no. 1, pp. 27-37. (in Russ.).

3. Babkin V.A, Ostroukhov L.A, Ivanova S.Z., Ivanova N.V., Medvedeva E.N., Malkov Iu.A., Trofimova N.N., Fedorov T.E. Zhurnal Rossiiskogo khimicheskogo obshchestva im. D.I. Mendeleeva, 2004, vol. 48, no. 3, pp. 62-69. (in Russ.).

4. Sukhov B.G., Aleksandrova G.P., Grishchsnko L.A., Feoktistova L.P., Sapozhnikov A.N., Proidakova O.A., T'kov A.V., Medvedeva S.A., Trofimov B.A. Zhurnal strukturnoi khimii, 2007, vol. 48, no. 5, pp. 979-984. (in Russ.).

5. Vasil'eva N.Yu., Levdansky A.V., Kuznetsov B.N., Skvortsova G.P., Kazachenko A.S., Djakovitch L., Pinel C. Russ. J. Bioorganic Chem., 2015, vol. 41, no. 7, pp. 725-731.

6. Vasil'eva N.Iu., Levdanskii A.V., Karacharov A.A. Mazurova E.V., Bondarenko G.N., Levdanskii V.A., Kazachenko A.S., Kuznetsov B.N. Zhurnal Sibirskogo federal'nogo universiteta. Khimiia, 2014, vol. 7, no. 4, pp. 547-555. (in Russ.).

7. Zagorodni A.A. Ion Exchange Materials: Properties and Applications. Amsterdam: Elsevier, 2006. 456 p.

8. Abragam A., Bleaney B. Electron Paramagnetic Resonance of Transition Ions. Oxford: Clarendon Press, 1970.700 p.

9. Al'tshuler S.A., Kozyrev B.M. Elektronnyi paramagnitnyi rezonans soedinenii elementov promezhutochnykh grupp. [Electron paramagnetic resonance of compounds of the elements of the intermediate groups]. Moscow, 1972, $670 \mathrm{p}$. (in Russ.).

10. Cheronis N.D., Ma T.S. Mikro- i polumikrometody organicheskogo funktsional'nogo analiza. [Micro- and polumikrometody organic functional analysis]. Moscow, 1973. 576 p. (in Russ.).

11. Podchainova V.N., Simonova L.N. Analiticheskaia khimiia elementov. Med'. [Analytical chemistry of elements. Copper]. Moscow, 1990, 279 p. (in Russ.).

12. Karaseva A.N., Mironov V.F., Tsepaeva O.V., Vyshtakaliuk A.B., Minzanova S.T., Karlin V.V., Mindubaev A.Z. Khimiia i komp'iuternoe modelirovanie. Butlerovskie soobshcheniia, 2004, vol. 5, no. 1, pp. 33-35. (in Russ.).

13. Krasil'nikova S.V., Grunin Iu.B., Smirnova L.G. Vishnevskaia G.P., Khong Ia.Sh., Li Ch.Kh., Volkov V.I. Struktura $i$ dinamika molekuliarnykh sistem, 2007, vol. 1, pp. 454-457. (in Russ.).

Received November18, 2016

Revised November 21, 2016

\footnotetext{
* Corresponding author.
} 
